Rainald Mössner

Christine M. Freitag

Martin Marziniak

Dirk Moser

Claudia Sommer

Jobst Meyer

\section{The functional Val158Met variant of the COMT gene is not associated with migraine with or without aura}

Received: 11 May 2006

Accepted in revised form: 12 May 2006

Published online: 15 June 2006
Dear Dr Martelletti,

Similar to Dr Hagen and colleagues [1] in The Journal of Headache and Pain, we were intrigued by the observation that genetic variants influence pain sensitivity in humans [2]. The enzyme catechol-O-methyltransferase (COMT) degrades catecholamines including dopamine. The functional variant of COMT, Val158Met, determines COMT enzyme activity, with the Met variant leading to a 3-4-fold lower enzyme activity, compared to the Val variant. The finding that the Val158Met genotype influences experimental pain sensitivity [2] led us to query whether this variant may contribute to the polygenic aetiology of migraine. The COMT activity of the genotypes is paralleled by the pain threshold, being lowest in met/met, intermediate in met/val and highest in $\mathrm{val} / \mathrm{val}$ [2]. We assessed a sample of 92 patients with migraine with aura, 127 patients with migraine without aura and 144 headache-free controls. Inclusion and exclusion criteria were as described previously [3]. Val158Met genotypes were in Hardy-Weinberg equilibrium for the patient and control groups. The frequency of the met/met genotype was $25 \%$ in migraine with aura, $23.6 \%$ in migraine without aura and $28.5 \%$ in controls. Conversely, val/val frequency was $30.4 \%$ in migraine with aura, $27.6 \%$ in migraine without aura and $25.7 \%$ in controls. There were no significant differences between groups as assessed by logistic regression, adjusted for sex dif- ferences (migraine with aura: Wald $\chi^{2}=0.86,2$ degrees of freedom, $p=0.65$; migraine without aura: Wald $\chi^{2}=0.51,2$ degrees of freedom, $p=0.77$ ). Thus, similar to the finding of Dr Hagen and colleagues in this journal, we do not find a contribution of the functional Val158Met variant of the COMT gene to the pathogenesis of migraine. This variant may be more important in tumour pain [4] and in tension headache [1] than in neuropathic pain [5] or in migraine.

Department of Psychiatry, University of Würzburg, Germany

R. Mössner (ه)

Department of Genetics and Applied Genomics, University of Toronto, Toronto Medical Discovery Tower, 101 College St., 14-701, Toronto, Ontario M5G 1L7, Canada e-mail: rainald.moessner@mail.uniwuerzburg.de

C.M. Freitag

Department of Child and Adolescent Psychiatry, University of Homburg,

Germany

M. Marziniak • C. Sommer Department of Neurology, University of Würzburg, Germany

M. Marziniak

Department of Neurology, University of Homburg, Germany

D. Moser - J. Meyer

Department of Neuro-Behavioral Genetics, University of Trier, Germany 


\section{References}

1. Hagen K, Pettersen E, Stovner LJ, Skorpen F, Zwart JA (2006) The association between headache and Val158Met polymorphism in the catechol-O-methyltransferase gene: the HUNT Study. J Headache Pain 7:70-74

2. Zubieta JK, Heitzeg MM, Smith YR, Bueller JA, Xu K, Xu Y, Koeppe RA, Stohler CS, Goldman D (2003) COMT val158met genotype affects mu-opioid neurotransmitter responses to a pain stressor. Science 299:1240-1243
3. Marziniak M, Mössner R, Schmitt A, Lesch KP, Sommer C (2005) A functional serotonin transporter gene polymorphism is associated with migraine with aura, Neurology 64:157-159

4. Rakvag TT, Klepstad P, Baar C, Kvam TM, Dale O, Kaasa S, Krokan HE, Skorpen F (2005) The Val158Met polymorphism of the human catecholO-methyltransferase (COMT) gene may influence morphine requirements in cancer pain patients. Pain 116:73-78
5. Armero P, Muriel C, Santos J, Sanchez-Montero FJ, Rodriguez RE, Gonzalez-Sarmiento R (2005) COMT (Val158Met) polymorphism is not associated to neuropathic pain in a Spanish population. Eur J Pain 9:229-232 